\title{
Nutrition Information on Packaged Foods Marketed in India: Disclosure Adequacy, Relevance, Use and Health Implications
}

\author{
Pavleen Soni ${ }^{*}$ and Kiranjot Kaur ${ }^{* *}$
}

Abstract

Health problems that stem from poor diet increase the need of nutrition labelling on food packages as it conveys meaningful information to consumers at the point of purchase and enables them to fulfill their dietary requirements. Nutrition labelling is relatively new to Indian markets, thus, the aim of this paper is to analyze the nature and extent of disclosure of nutrition information on packaged foods in India, its adequacy, nutrition quality of marketed foods according to UK traffic light food labelling criteria and consumer use of nutrition information. Primary data collected from 230 food packages have been content analyzed which reveal that although nutrition labels are present on the majority of sampled foods, yet, disclosure of mandatory nutrients is not adequate. Also, the majority of packaged foods are found to be unhealthy. Further, from a sample of 600 consumers, information was collected about nutrition knowledge, use and the reasons for not using nutrition information on food labels. It was found that consumers possess knowledge about total fat, protein, vitamins and minerals. The present study adds to existing knowledge by providing an understanding level of disclosure of nutrition information, its effectiveness when used by consumers and health implications of these disclosures to gauge the extent to which the disclosures are adequate in promoting healthful choices amongst consumers. Policy implications have also been identified that will help regulatory authorities to draft measures required for promoting health of Indian consumers.

Keywords: Nutrition Labelling, Packaged Foods, Health, Policy Implications.

\section{INTRODUCTION}

Nutrition labelling has been considered as a legitimate tool to support the goal of promoting healthy eating by the public health community, government and food companies (Genannt Bonsmann et al., 2010; Vijaykumar et al. 2013; Connoosamy et al., 2014). It has been recognized that nutrition labelling is used by consumers and affects their purchase decisions (Shine et al., 1997; Cowburn and Stockley, 2004; Satia et al., 2005). Conformance to regulations relating to disclosure of nutrition information can lead to uniformity in disclosures on nutrition labels. This will help consumers learn to understand nutrition information, enable comparison of nutrient content and help them choose foods as per their dietary preferences.

\footnotetext{
Associate Professor, University Business School, Guru Nanak Dev University, Amritsar, India. . E-mail: pavleen.soni@gmail.com

** Assistant Professor, PG Department of Commerce and Management, Khalsa College for Women, Amritsar, India. E-mail: kiranjot.kaur87@gmail.com(Corresponding Author)
} 
International standards regarding nutrition labelling have been developed by Codex Alimentarius Commission in collaboration with the World Trade Organization to protect consumer health around the world (Hawkes and World Health Organization, 2004). Need for nutrition labelling has long been identified in developed countries. Rapid increase in incidence of non-communicable diseases (NCDs) and other health issues that arise from consumption of poor diets pointed to the need for food labelling. Consequently, the majority of packaged foods marketed in those countries started carrying nutrition labels (Brecher et al., 2000; Legault et al., 2004; Brandt, Moss and Ferguson, 2009). Subsequently, governments in many developing countries like India and China witnessed an increase in prevalence of NCDs and realized the importance of nutrition in human health. Thereafter, they made it obligatory for food marketing companies to declare nutrition information on food labels. In India, Food Safety and Standards Authority of India (FSSAI) regulates labelling of packaged foods since 2006. Initially, labelling of packaged food was restricted to only general information like name of the food, price and quantity of the product, ingredients and manufacturer's identity (Singla, 2010; Srivastava and Ghufran, 2013). But in 2009, FSSAI identified some nutrients which it made mandatory for companies to label on packaged foods. New guidelines were further added and detailed provisions regarding disclosure of nutrients were provided in the draft report of "Regulations on labelling (claims)", 2012. These regulations provided direction and the form in which nutrition information such as nutrients and claims should appear on food packages.

\section{REVIEW OF LITERATURE}

Research prior to introduction of food labelling regulations by FSSAI found that Indian consumers do not use a lot of information from food labels as they find it complex to understand and also lack nutrition education (Saha et al., 2013; Vemula et al., 2013). When information on portion sizes is provided, consumers are able to read labels in a better way (Singla, 2010). A recent study conducted after introduction of food labelling regulations by Kumar and Kapoor (2017) revealed that Indian consumers read food labels before making purchase decisions. Consumer food label reading is associated with label use (Dharni and Gupta, 2015) but they find labels difficult to read due to small font, incomplete labelling and hidden information (Dutta and Patel, 2017). Indian consumers are health conscious but prefer convenience in buying (Kumar and Kapoor, 2017; Dutta and Patel, 2017). When disclosure of nutrition is followed uniformly by food marketing companies; interventions related to nutrition education of consumers can be initiated. These interventions are found to influence diet related perceptions and behavior of consumers (Govindasamy and Italia, 1999; Cowburn and Stockley, 2005).

Investigation of disclosures on food labels are important as previous studies have found that information on the extent of disclosure of nutrition information on food labels is useful while conducting studies on consumers' use of nutrition labelling. For example, Genannt Bonsmann et al. (2010) explored the penetration of nutrition information on food labels in order to investigate the impact of use of this information on consumer shopping behavior. Some surveys such as Food Label and Package Survey (FLAPS) have been conducted by Food and Drug Administration (FDA) on nutrition labelling over a period of time in order to observe the food marketer's response to labelling regulations (Brecher et al., 2000; LeGault et al., 2004; Brandt, Moss and Ferguson, 2009). Similarly, Kasapila and Shaarani (2013) have also focused on nutrition labelling. They explored the prevalence of nutrition labelling on packaged foods so that opportunities for improvement in labelling can be identified. Although some studies investigated nutrition labelling practices in developed countries (Brandt, Moss and Ferguson, 2009; Genannt Bonsmann et al., 2010; Brecher et al., 2000; LeGault et al., 2004; Brandt, Moss and Ferguson, 2009), yet, only a few have examined nutrition information on food labels in developing countries (Lv et al., 2011; Kasapila and Shaarani, 2013). 


\section{PURPOSE OF THE STUDY}

Not much is known about the manner in which nutrient information is disclosed by food marketing companies in India after comprehensive guidelines have been given by the FSSAI. As the state of regulations varies across countries, there is a need to understand the state of nutrition labelling in diverse countries for policy formulation and stringent regulations. More so, consumer response to nutrition labelling also varies across socio-economic characteristics of consumers (Aygen, 2012; Besler et al., 2012; Cannoosamy, Pugo-Gunsam and Jeewon, 2014). So an attempt has been made in this paper to answer the following research questions:

RQ1: What is the nature and extent of disclosure of nutrition information on food labels? Is mandatory information adequately disclosed? What kind of voluntary information is disclosed by companies? Are the disclosures same across Indian companies and MNCs?

RQ2: Are all relevant nutrients disclosed on packaged foods? For example—sugar on sweetened foods and sodium on salty foods.

RQ3: Are the packaged foods healthy according to UK Traffic Light criteria? Can disclosures be misleading?

RQ4: Is nutrition information used by the consumers while taking buying decisions? What is the extent of nutrition knowledge and use of nutrition information from food labels?

\section{METHODOLOGY}

\section{Selection offood companies, food categories and respondents}

Fourteen leading packaged food companies have been considered for selection of food products to record presence of nutrition information as defined in the report of Indian Food Processing Industries given by India Law Offices (Available at http://www.indialawoffices.com/ilo_pdf/641469785421.pdf). Nine relevant food categories have been selected out of eighteen food categories from the report of "Indian Food Code" for categorization of food defined by Food Safety and Standard Authority of India (FSSAI). As data regarding food labelling was required, nine food categories related to packaged foods only were considered for this study and other food categories based on eggs, meat, fish, fruits and vegetables were not included. The selected food categories were: Bakery Products, Beverages excluding Dairy Products, Cereals and Cereal Products, Confectionery, Dairy Products and Analogues, Fats and Oils and Fats Emulsions, Foodstuffs Intended for Particular Nutritional Uses, Ready-To-Eat Savouries and Salt, Spices, Soups, Sauces, Salads and Protein Products. Moreover, foods belonging to these categories have also been found to be highly marketed by food companies in India (Soni, 2016).

\section{Sampling}

For data collection, websites of selected fourteen companies were visited and available brands were listed. All the variants of a product were considered as different food products for the purpose of this study but flavors were counted as one product. Out of the listed 367 products, 230 products were brought from the market. The packages were sampled from January, 2016 to March, 2016. 


\section{Data collection}

The draft report of "Regulations on labelling (claims)", 2012 given by FSSAI has been used to prepare a code book that defines all the nutrient information extracted from packaged foods such as a list of mandatory nutrients that need to be displayed on labels. Primary data was obtained from a nutrition information panel (NIP) displayed on the back of the packages and two coders independently coded the items (inter-coder reliability 96 percent). Data collected through content analysis has been recorded in a spreadsheet prepared in Microsoft Excel 2007 and transferred to SPSS for analysis.

\section{Data analysis}

Nutrition information was extracted from the nutrition information panel by categorizing the nutrients as mandatory and voluntary nutrients. Then adequacy of these nutrients has been checked by analyzing sweet and salty products. Further, using the Traffic Light Criteria, specific nutrients have been investigated to check their healthiness for consumption. Lastly, consumers' aspect has also been analyzed to check the usage of displayed nutrition information by the consumers.

\section{Consumer survey}

In order to measure the extent of nutrition information usage by consumers, convenience cum judgmental sampling was used to collect data from 600 consumers (503 effectively used) in three districts of Punjab viz. Amritsar, Jalandhar and Ludhiana. Using mall intercept technique information was collected from those consumers who were the primary food shoppers of their household. The respondents were asked to specify the extent to which they used food labels and the nutrition information they sought from food packages. Most of the respondents were females $(73.16 \%)$, in the age group $25-34$ years $(47.51 \%)$, with average monthly income between INR 50,000$1,00,000(32.60 \%)(\$ 702-1404)$ and were occupied in profession $(26.24 \%)$ and service $(25.45 \%)$.

\section{FINDINGS AND DISCUSSION}

\section{Products surveyed}

A total of 230 food packages were analyzed for disclosure of nutrition labelling by grouping food products into nine food categories identified as bakery products $(24.78 \%)$, beverages, excluding dairy products $(11.74 \%)$, cereals and cereal products $(10.87 \%)$, confectionery $(6.52 \%)$, dairy products and analogues $(16.52 \%)$, fats and oils, and fats emulsions (5.22\%), foodstuffs intended for particular nutritional uses (3.04\%), ready-to-eat savouries (17.83\%) and salt, spices, soups, sauces, salads and protein products $(3.48 \%)$.

RQ1. What is the nature and extent of disclosure of nutrition information on food labels? Is mandatory information adequately disclosed? What kind of voluntary information is disclosed by companies? Is that nature and extent of disclosure same across Indian companies and MNCs?

\section{Nutrition labelling}

Information gathered about nutrition labelling on food packages revealed that food marketing companies fulfill basic requirements by displaying nutrition facts panel on majority of food packages (98.7\%). According to Draft 
regulations of FSSAI, mandatory information is necessary to declare on food labels; while disclosure of information about other nutrients is voluntary. Therefore, disclosure of nutrition information has been segregated as - mandatory nutrition information and voluntary nutrition information. Disclosure of nutrition information is found to vary across Indian companies and MNCs (Consumers International, 2008). So, disclosures have been compared across these companies using the chi-square test. The results in this regard are presented in the subsequent paragraphs.

\section{Disclosure of nutrients in the mandatory list}

Mandatory information includes information on energy, protein, total carbohydrates, total sugars, added sugar, total fat, saturated fat, transfats, cholesterol and sodium on food labels. However, Table 1 shows that none of the nutrients have been fully disclosed on the sampled products. The nutrients that companies choose to highly disclose include protein (98.3\%), total carbohydrates (98.3\%), total fat (98.3\%) and energy (97.4\%). These were followed by information on saturated fat, transfats and total sugars for 86.1 percent, 80 per cent and 77 per cent foods respectively. Even though nutrients like sodium, cholesterol and added sugar should be definitely declared on food labels, their disclosure was seen to be low. Sodium was listed on 38.3 percent products only while cholesterol was listed on 32.6 percent products. Added sugar was the least disclosed nutrient from the list of mandatory nutrients as nearly twenty percent products contained this information.

Table 1: Disclosure of mandatory nutrients

\begin{tabular}{|l|c|c|c|c|c|c|c|c|}
\hline \multirow{2}{*}{$\begin{array}{l}\text { Mandatory } \\
\text { nutrients }\end{array}$} & \multicolumn{2}{|c|}{$\begin{array}{c}\text { Total products } \\
\text { (230) }\end{array}$} & \multicolumn{2}{|c|}{$\begin{array}{c}\text { Indian companies } \\
\text { (121) }\end{array}$} & \multicolumn{2}{|c|}{$\begin{array}{c}\text { MNCs } \\
(\mathbf{1 0 9 )}\end{array}$} & \multirow{2}{*}{$\chi^{\mathbf{2}}$} & \multirow{2}{*}{ P } \\
\cline { 2 - 8 } Energy & 224 & 97.4 & 115 & 95.0 & 109 & 100 & 5.550 & $\mathbf{0 . 0 3 0 ^ { * }}$ \\
\hline Protein & 226 & 98.3 & 117 & 96.7 & 109 & 100 & 3.667 & $0.124^{*}$ \\
\hline Total carbohydrates & 226 & 98.3 & 117 & 96.7 & 109 & 100 & 3.667 & $0.124^{*}$ \\
\hline Total sugars & 177 & 77.0 & 81 & 66.9 & 96 & 88.1 & 14.439 & $\mathbf{0 . 0 0 0}$ \\
\hline Added sugar & 45 & 19.6 & 36 & 29.8 & 9 & 8.3 & 16.836 & $\mathbf{0 . 0 0 0}$ \\
\hline Total fat & 226 & 98.3 & 117 & 96.7 & 109 & 100 & 3.667 & $0.124^{*}$ \\
\hline Total saturated fat & 198 & 86.1 & 105 & 86.8 & 93 & 85.3 & 0.101 & 0.750 \\
\hline Transfat & 184 & 80.0 & 86 & 71.1 & 98 & 78.9 & 0.157 & 0.692 \\
\hline Cholesterol & 75 & 32.6 & 31 & 25.6 & 44 & 40.4 & 5.675 & $\mathbf{0 . 0 1 7}$ \\
\hline Sodium & 88 & 38.3 & 45 & 37.2 & 43 & 39.4 & 0.124 & 0.725 \\
\hline
\end{tabular}

*denotes value according to fisher's exact test. 
Information on mandatory nutrients has been further cross classified across Indian companies and MNCs. Table 1 shows that Indian companies do not fully comply with the disclosure requirements for any nutrient. But MNCs have made disclosures on all products for energy, protein, total carbohydrates and total fat. Chi-square test results also show that statistically significant differences exist in disclosure of nutrients across Indian companies and MNCs for disclosure of energy, total sugar, added sugar and cholesterol $(p<0.05)$. The results reveal no statistically significant differences for disclosure of other mandatory nutrients on food packages.

\section{Voluntary disclosure of nutrients}

Many companies voluntarily disclose certain nutrients (mainly vitamins and minerals) in the nutrition information panel. Table 2 reveals information on presence of vitamins on food packages. The commonly declared vitamins on food packages were vitamin A and B. Disclosure of vitamin B (including vitamin B1, B2, B3, B5, B6, B9 and B12) was found on 15.7 percent of food products followed by vitamin A (13.91\%). Regarding disclosure of minerals, calcium was found to be the most frequently labeled mineral (22.17\%). Besides vitamins and minerals, fiber, polyunsaturated fatty acids (PFA) and monounsaturated fatty acids (MFA) were also disclosed on nearly one fourth of sampled products.

Table 2: Disclosure of voluntary nutrients

\begin{tabular}{|c|c|c|c|c|c|c|c|c|}
\hline \multirow[t]{2}{*}{$\begin{array}{l}\text { Voluntary } \\
\text { Nutrients }\end{array}$} & \multicolumn{2}{|c|}{$\begin{array}{c}\text { Total products } \\
\text { (230) }\end{array}$} & \multicolumn{2}{|c|}{$\begin{array}{c}\text { Indian companies } \\
\text { (121) }\end{array}$} & \multicolumn{2}{|c|}{$\begin{array}{l}\text { MNC } \\
(109)\end{array}$} & \multirow[t]{2}{*}{$\chi^{2}$} & \multirow[t]{2}{*}{$\mathbf{P}$} \\
\hline & $\mathrm{N}$ & $\%$ & $\mathrm{~N}$ & $\%$ & $\mathrm{~N}$ & $\%$ & & \\
\hline Vitamin A & 32 & 13.9 & 19 & 15.7 & 13 & 11.9 & 0.683 & 0.409 \\
\hline Vitamin B & 36 & 15.7 & 20 & 16.5 & 16 & 14.7 & 0.149 & 0.700 \\
\hline Calcium & 51 & 22.2 & 29 & 24.0 & 22 & 20.2 & 0.476 & 0.490 \\
\hline Fibre & 54 & 23.5 & 13 & 10.7 & 41 & 37.6 & 23.046 & 0.000 \\
\hline $\begin{array}{l}\text { Polyunsaturated } \\
\text { fatty acids (PFA) }\end{array}$ & 57 & 24.8 & 20 & 16.5 & 37 & 33.9 & 9.331 & 0.002 \\
\hline $\begin{array}{l}\text { Monounsaturated } \\
\text { fatty acids (MFA) }\end{array}$ & 57 & 24.8 & 20 & 16.5 & 37 & 33.9 & 9.331 & 0.002 \\
\hline
\end{tabular}

Chi-square has been used again to identify whether voluntary disclosures varied across Indian companies and MNCs. The results revealed that MNCs make significantly higher disclosure of nutrients viz. fibre, PFA and MFA than Indian companies $(\mathrm{P}<0.05)$. Indian companies make higher disclosure of vitamins and minerals than MNCs.

Since foods have not been found to completely disclose all nutrients specified in the mandatory list, adequacy of disclosure has been checked through disclosure of sodium on salty products and disclosure of sugar on sweet products. 
RQ2. Are all relevant nutrients disclosed on packaged foods? For example sugar on sweetened foods and sodium on salty foods.

\section{Analysis of products for disclosure of relevant nutrients}

128 sweet foods and 88 salty foods have been identified for analyzing disclosure of information in relation to sugar and salt respectively (refer Table 3). It has been identified that even when the nature of food was sweet and salty, information about added sugar, total sugar and sodium were not found on 73.4 percent, 25.8 percent and 44.3 percent products respectively. Across food categories, added sugar was not disclosed on bakery products (100\%) followed by confectionery $(86.7 \%)$, cereals and cereal products $(75 \%)$ and foodstuffs intended for particular nutritional uses $(71.4 \%)$. For more than half $(52.2 \%)$ of the products in the category beverages, excluding dairy products added sugar was not disclosed. Whereas, non-disclosure of total sugar was found to be high in foods falling into the category - foodstuffs intended for particular nutritional uses (71.4\%) and dairy products and analogues (60\%). Regarding salty products, disclosure of sodium was not available on bakery products followed by categories - salts, spices, soups, sauces, salads and protein products (50.0\%), ready-to-eat savouries (43.90\%), cereals and cereal products (31.6\%) and fats and oils and fat emulsions $(25.0 \%)$.

Table 3: Disclosure of sugar and sodium on sweet and salty products

\begin{tabular}{|l|c|c|c|c|c|}
\hline Category & $\begin{array}{c}\text { Total } \\
\text { sweet } \\
\text { products } \\
\text { N }\end{array}$ & $\begin{array}{c}\text { Non-disclosure } \\
\text { of added sugar } \\
\text { N }(\%)\end{array}$ & $\begin{array}{c}\text { Non-disclosure } \\
\text { of total sugar } \\
\text { N }(\%)\end{array}$ & $\begin{array}{c}\text { Total salty } \\
\text { products } \\
\mathbf{N}\end{array}$ & $\begin{array}{c}\text { Non- } \\
\text { disclosure of } \\
\text { sodium } \\
\text { N (\%) }\end{array}$ \\
\hline Bakery products & $\mathbf{4 9}$ & $49(100)$ & $0(0)$ & $\mathbf{9}$ & $9(100)$ \\
\hline $\begin{array}{l}\text { Beverages, excluding dairy } \\
\text { products }\end{array}$ & $\mathbf{2 3}$ & $12(52.2)$ & $7(30.4)$ & - & - \\
\hline Cereals and cereal products & $\mathbf{4}$ & $3(75)$ & $1(25)$ & $\mathbf{1 9}$ & $6(31.6)$ \\
\hline Confectionery & $\mathbf{1 5}$ & $13(86.7)$ & $2(13.3)$ & - & - \\
\hline $\begin{array}{l}\text { Dairy products and } \\
\text { analogues }\end{array}$ & $\mathbf{3 0}$ & $12(40)$ & $18(60)$ & $\mathbf{7}$ & $1(12.3)$ \\
\hline $\begin{array}{l}\text { Fats and oils and fats } \\
\text { emulsions }\end{array}$ & - & - & - & $\mathbf{4}$ & $1(25)$ \\
\hline $\begin{array}{l}\text { Foodstuffs intended for } \\
\text { particular nutritional uses }\end{array}$ & $\mathbf{7}$ & $5(71.4)$ & $5(71.4)$ & - & - \\
\hline Ready-to-eat savouries & - & - & - & $\mathbf{4 1}$ & $18(43.9)$ \\
\hline $\begin{array}{l}\text { Salts, spices, soups, sauces, } \\
\text { salads and protein products }\end{array}$ & - & - & - & $\mathbf{8}$ & $4(50)$ \\
\hline Total & $\mathbf{1 2 8}$ & $94(73.4)$ & $33(25.8)$ & $\mathbf{8 8}$ & $39(44.3)$ \\
\hline
\end{tabular}


Besides disclosure about presence of nutrients, it is important to understand the quantity of nutrients in foods. Disclosure of nutrient information is necessary in order to inform consumers about the nutrient composition of foods. But some nutrients like fat, sodium and sugar should not be over consumed. Packaged foods have been identified to contain high content of fat, sugar \& salt and are termed as HFSS foods (Cairns, Angus and Hastings, 2009). Therefore, it is sought to identify the extent of disclosure of these nutrients in foods marketed in India.

RQ3. Are the packaged foods healthy according to UK Traffic Light criteria? Can disclosures be misleading?

Finally, UK Traffic light criteria (TLC) have been used to explore whether foods marketed in India are healthy or unhealthy. TLC is a front of pack food labelling scheme firstly adopted in the United Kingdom in 2006 on the recommendation of the Food Standard Agency (FSA). This color coded scheme highlights the four key nutrients viz. total fat, saturated fat, sugar and sodium with red, amber and green color to represent high, medium and low levels of nutrients respectively. As this system is very useful in highlighting healthy and unhealthy products, consumer organizations in Europe (Lobstein and Davies, 2008) and Australia (Sacks et. al., 2011) have supported it. The cut offs for these signals are widely acceptable as these are consistent with the international trade requirements for nutrition related claims specified by Codex Alimentarius Commission (Lobstein and Davies, 2008). So in this section, using the same criteria, packaged foods marketed in India have been classified on the basis of red, amber and green color codes highlighting the content of sugar, sodium and fats.

\section{Classifying food products using UK front of pack traffic light food labelling criteria}

On each of the 230 packaged foods, disclosure of total sugars, total fat, total saturated fat and sodium has been checked to see whether they could be evaluated according to conditions specified for using TLC. The eligible products are shown in Table 4. From the eligible products, more than fifty percent products were found to be high in total saturated fat and total fat represented by color code "red". Low content of total sugars $(36.9 \%)$, total fat (19.2\%), total saturated fat (19.6\%) and sodium (42\%) represented by color code "green" show the proportion of healthy foods available for consumption. Consequently, TLC revealed that most of the packaged foods available for consumption were unhealthy.

Table 4: Analysis of total sugars, total fat, total saturated fat and sodium from packaged foods using TLC

\begin{tabular}{|l|c|c|c|c|}
\hline Color codes & Total Sugars & Total Fat & $\begin{array}{c}\text { Total Saturated } \\
\text { Fat }\end{array}$ & Sodium \\
\hline Green & $62(36.90)$ & $38(19.19)$ & $22(19.64)$ & $34(42.00)$ \\
\hline Amber & $42(25.00)$ & $56(28.28)$ & $22(19.64)$ & $41(50.62)$ \\
\hline Red & $64(38.10)$ & $104(52.53)$ & $68(60.71)$ & $06(7.41)$ \\
\hline Total products analysed & $168(73.04)$ & $198(86.09)$ & $112(48.70)$ & $81(35.22)$ \\
\hline
\end{tabular}




\section{Analysis of red code foods across food categories}

TLC highlighted products with high, medium and low content of negative nutrients (fat, sugar and salt) represented by red, amber and green color codes. Red (high) code foods have been further analysed across foods categories for deeper insight into specific food categories that can be classified as unhealthy. Figure 1 shows that confectionery contains high amount of sugar and fats. Ready-to-eat savouries contain high quantities of total fat and total saturated fat. Large numbers of bakery foods were high in total saturated foods. These food categories are hence identified to be very unhealthy. Sodium has not been analysed across food categories as only 6 foods have been noticed in red color code.

Fig. 1: Analysis of high (red) content of total sugars, total fat and total saturated fat across food categories

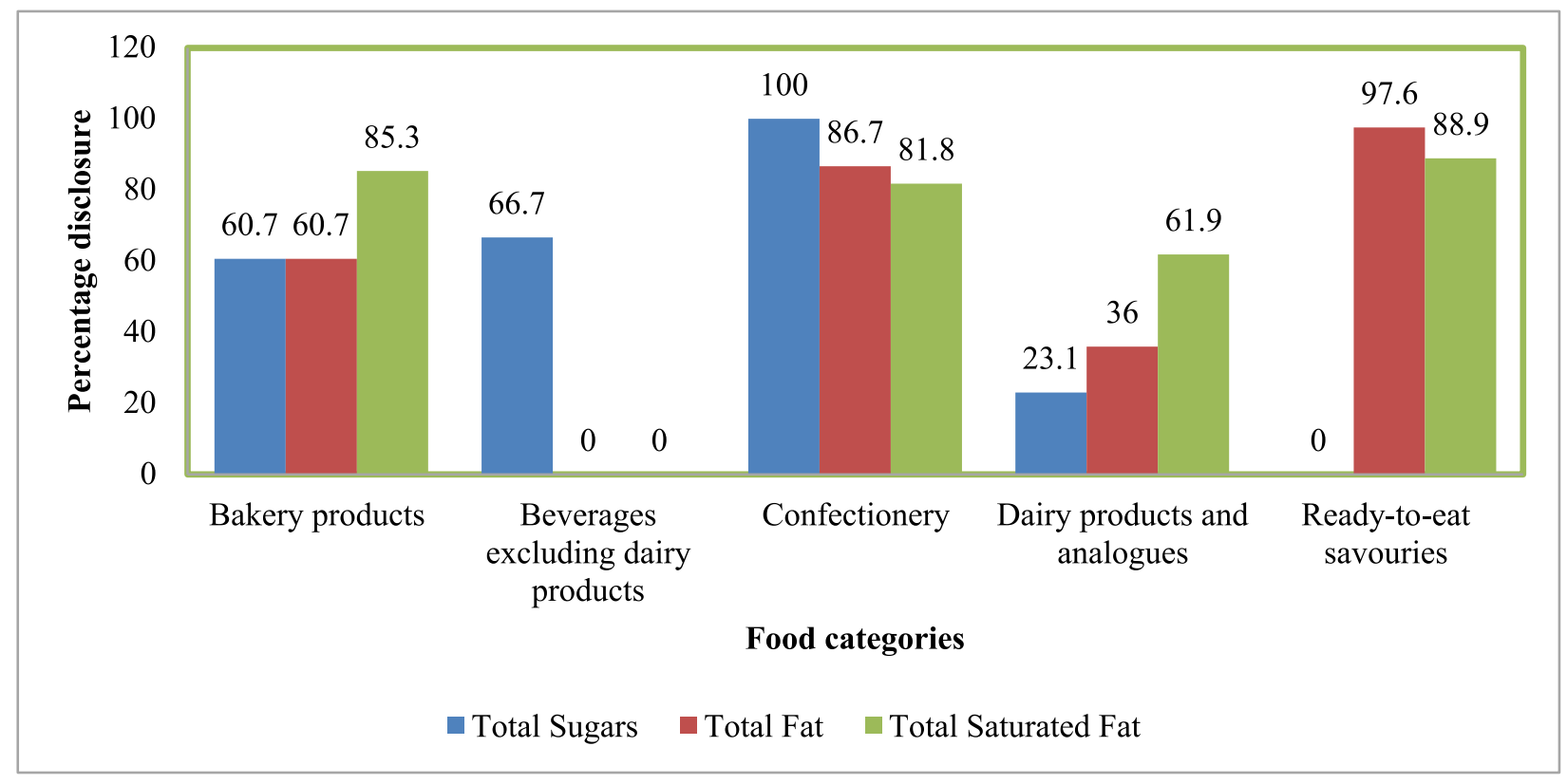

It has been reported earlier that in order to reduce the quantity of sugar in a product, salt content is increased and both are used as substitutes (Consumers International, 2008). The overall impact of the product remains unhealthy although the product falls in the green category for sugar according to TLC. Therefore, after analyzing red code foods, low sugar foods (green code) were also investigated to find out whether these foods were also low in sodium. The analysis revealed that the majority of low sugared foods either did not disclose sodium (55.0\%) or were not low in sodium content $(41.7 \%)$.

The above discussion shows the extent of disclosure of nutrition information on food labels. Information provided on food labels is relevant only if it is used by consumers. So, there is a need to investigate consumers' perspective also i.e. how important is the nutrition information provided on food labels for the consumers while taking purchase decisions.

RQ4: Is nutrition information used by the consumers while taking buying decisions? What is the extent of nutrition knowledge and use of nutrition information from food labels? 
Further, consumer use of nutrition information has been investigated because disclosures will provide positive health outcomes only if consumers know about them and use them. Consumer responses related to nutrition knowledge, use of nutrition information and reasons for not using nutrition information have been analysed next.

Table 5: Analysis of proportion of respondent's knowledge and usage of nutrition information from food labels

\begin{tabular}{|l|c|c|}
\hline Nutrients & $\begin{array}{c}\text { Respondents having nutrition } \\
\text { knowledge }\end{array}$ & $\begin{array}{c}\text { Respondents' use of nutrition } \\
\text { information from labels }\end{array}$ \\
\hline Calories(Energy) & $140(27.8)$ & $239(47.5)$ \\
\hline Sodium & $53(10.5)$ & $196(39.0)$ \\
\hline Total fat & $247(49.1)$ & $258(51.3)$ \\
\hline Saturated fat & $41(8.2)$ & $214(42.5)$ \\
\hline Cholesterol & $60(11.9)$ & $251(49.9)$ \\
\hline Vitamins and minerals & $193(38.4)$ & $226(44.9)$ \\
\hline Fiber & $46(9.1)$ & $245(48.7)$ \\
\hline Sugars & $116(23.1)$ & \\
\hline Others & Protein (39.4), total carbohydrates (30.2), \\
transfat (8.2), calcium (14.3) & \\
\hline
\end{tabular}

Figures in parentheses denote percentages

In order to check nutrition knowledge of consumers, they were asked to recall the nutrients seen on food packages and for checking use of nutrition information from food labels, they were provided with the list of nutrients. Respondents were able to recall information on total fat (49.1\%), protein (39.4\%) and vitamins and minerals (38.4\%). They were also aware about information on nutrients viz. total carbohydrates (30.2\%), calories (27.8\%), sugars (23.1\%), calcium (14.3\%), cholesterol (11.9\%), sodium (10.5\%) fiber (9.1\%) and transfat $(8.2 \%)$.

Table 5 shows that most of the consumers 'use' information on total fat (51.3\%), vitamins and minerals (49.9\%), sugars (48.7\%), cholesterol (48.5\%) and energy (47.5\%) while buying foods. Information on total fat was mostly considered and read from food labels.

As only a small proportion of consumers use nutrition information on food labels, the reasons for not reading the food label have also been identified and shown in Table 6. 
Table 6: Reasons for not reading nutrition information

\begin{tabular}{|llr|}
\hline \multicolumn{1}{|c}{ Reasons } & $\mathbf{N}$ & \% \\
I prefer getting nutrition information from other sources besides the food label & 235 & 46.72 \\
It takes too much time to read the food label & 232 & 46.12 \\
The information on food label is hard for me to understand & 207 & 41.15 \\
I don't need to use food label since I already know what foods to eat & 189 & 37.57 \\
I am just not interested in the nutrition information on food labels & 180 & 35.79 \\
\hline
\end{tabular}

Table 6 reveals that most of the consumers (46.72\%) prefer to get nutrition information from other sources besides the food label probably because nearly forty six percent respondents think that reading food labels is time consuming. About forty percent consumers also find nutrition information difficult to understand. Nearly thirty eight percent of consumers think that they don't need to use a food label since they already know what foods to eat and thirty six percent respondents were not interested in the nutrition information on food labels.

\section{Policy implications}

This paper provides detailed insight about nutrition information on food labels marketed in India. It is seen that the majority of foods carry nutrition facts label and display nutrient value using per $100 \mathrm{~g} / \mathrm{ml}$ reference unit. These products satisfy the conditions laid down by FSSAI that allow using any reference unit like per $100 \mathrm{~g}$ or per $100 \mathrm{ml}$ or per serving. But as reference values are not given with per $100 \mathrm{~g} / \mathrm{ml}$, consumers are not able to compare food intake with recommended nutrient value for their daily requirements (Singh, Iyer and Chandorkar, 2013). Consequently, it is suggested that policy makers should make it mandatory to declare percent daily value in the nutrition facts panel along with existing format so that it is obligatory for marketer to disclose. This format is very helpful in managing diet (Levy, Fein and Schucker, 1996; Drichoutis, Lazaridis and Nayga, 2006) and enables consumers to know whether the content of nutrients in a particular food is high or low (Drichoutis, Lazaridis and Nayga, 2006).

The present findings reveal that highly disclosed nutrients on food labels include total carbohydrates, total fats and proteins. These three macronutrients are essential for human health and are required in large amounts (National Institute of Nutrition, 2011). Disclosure of these nutrients on food packages enables consumers to make need based food choices. Consumer responses also show that information on total fat, protein, vitamins and minerals is sought by consumers while buying foods. This is however, accompanied with limited disclosure of nutrients like sodium (38.26\%), cholesterol (32.61\%) and added sugar (19.57\%), even though these are mandatory to declare on food labels. These nutrients have adverse effects on human health if consumed in large quantities. More so, Indian companies have been found to make lesser disclosures as compared to MNCs. Therefore, it draws attention towards the need for stringent enforcement of regulations on marketers and penalties should be framed for noncompliance of disclosure of mandatory information. Additionally, the majority of consumers also do not look for information on sodium and sugar probably because of lack of knowledge and understanding. 


\section{Practical implications}

It is worth highlighting that from identified sweet and salty products, a large number of products do not disclose sugar and sodium. By concealing important information, for example, added sugar from food categories viz., bakery products, confectionery, cereals and cereals products; total sugars from food categories such as foodstuffs intended for particular nutritional uses and dairy products and analogues; and sodium from foods such as bakery products, salts, spices, soups, sauces, salads and protein products and ready-to-eat savouries, marketers tend to mislead consumers by projecting that these products do not contain these nutrients. With non-disclosure of nutrients, marketers also violate the provision of consumers' "right to know" about purchased products. Cowburn and Stockley (2005) pointed out that consumers have the right to know about the nutrient content of a food. These are important issues from a public health perspective as diet related non communicable diseases like obesity, coronary heart diseases, blood pressure and diabetes are increasing globally (Drichoutis, Lazaridis and Nayga, 2006; World Health Organization, 2011). With the changing lifestyles and consumption habits, they are rising rapidly in India too (Popkin, 2009; Intodia, 2011). Thus, it requires the attention of policy makers and the need for policy actions to curb these misleading practices.

Upon evaluating packaged foods according to front of pack traffic light food labelling criteria, it was revealed that the majority of packaged food products contain high content of total sugars, total fat and total saturated fat (refer Table 4). According to TLC, confectionery, bakery and ready-to-eat savouries form the unhealthiest products. The foods belonging to the category - beverages, excluding dairy products, seem to contain healthy products as they have low content of total fat, total saturated fat and sodium but due to high content of total sugar in majority of foods, it is not healthy actually. It depicts that the majority of the investigated products fall into 'red' code whereas only few products found to fall into 'green' code. It is also interesting to note that the same products were not simultaneously low in both sugar and salt content. That is, the low content of salt in the food was accompanied with high content of sugar. Consequently, packaged foods available to consumers for consumption in India are generally unhealthy. As foods belonging to these categories are also found to be highly consumed in India (Soni, 2016) these may adversely affect health of consumers. This highlights the need for more-intense consumer education (Kresic et al., 2018) on part of the policy makers, the government and the regulators. NIN should create awareness about the Food Pyramid that highlights the proportion of consumption of processed foods, whole grains and cereals and fresh fruits and vegetables in their diet. In order to monitor and regulate consumption of unhealthy foods, some simplified and universal labelling criteria such as the traffic light system adopted in many developed countries should be used in India too. This technique is identified to be very helpful in improving consumers' understanding of nutrition information (Hawley at al., 2013) as it clearly differentiates between healthy and unhealthy products using color codes for four core nutrients. This is easy to understand for less literate people as well who form the masses in the Indian economy. Moreover, low involvement during food purchases on part of consumers probably due to shortage of time (Kelly et al., 2008) or rigorous information provided on packaged foods that is hard to interpret and confusing for consumers (Cowburn and Stockley, 2005) influences use of nutrition information on food labels. In such situations, indicators in front of important nutrients are extremely helpful to consumers as it was reported to be a useful technique in a survey for 90 percent consumers (Cooperative Wholesale Society, 2002 cited from Drichoutis, Lazaridis and Nayga, 2006).

Consumer education about use of food labels is essential as more than forty percent consumers prefer getting nutrition information from other sources besides the food label, find the information hard to understand or find reading it time consuming. Use of symbols or colors can serve to ease the task of reading and interpreting nutrition information. The nutrition facts panel must provide nutrition information in readable font sizes and the legislators should add provisions about font sizes proportionate to package sizes which should be used to make depictions in 
nutrition facts panel.

Nonetheless, grocery purchases over the internet are increasing (Morgan Stanley Research, 2016). Social media marketing is also emerging as a marketing tool for the packaged food industry (Rajput, 2015). As marketing through these mediums is rapidly emerging, this raises concern about disclosures of nutrition information on food labels through these media. It is also observed that there is a huge difference in information content of nutrition facts panels displayed on food packages between foods available in the market and the ones displayed on websites. It points to the need for guidelines and regulations for e-commerce sites as currently no policies have been framed that define rules for selling foods online (Sarkar, 2017).

\section{LIMITATIONS AND DIRECTIONS FOR FUTURE RESEARCH}

The present study has some limitations so these should be acknowledged. Firstly, products of fourteen leading companies (national and MNCs) have been analyzed for disclosure of nutrition information while local companies have not been included. They can be considered in future studies for deeper insight into disclosures. Store audit can be conducted to analyze products and brands completely. Secondly, this is not a longitudinal study. So the same can be done to analyze the trends over a period of time to understand conformance to guidelines. Lastly, due to time and cost constraints, nature and extent of disclosure of nutrients only has been recorded in the present study. Other marketing strategies such as claims used on food packages to attract customers have not been considered. So these can be explored in future studies.

\section{REFERENCES}

Aygen, F. G. (2012). Turkish consumers' understanding and use of nutrition labels on packaged food products, International Journal of Business and Social Science, 3(6), 171-183.

Besler, H. T., Buyuktuncer, Z., \& Uyar, M. F. (2012). Consumer understanding and use of food and nutrition labeling in Turkey, Journal of Nutrition Education and Behavior, 44(6), 584-591.

Brandt, M., Moss, J., \& Ferguson, M. (2009). The 2006-2007 Food Label and Package Survey (FLAPS): nutrition labeling, trans fat labeling, Journal of Food Composition and Analysis, 22, S74-S77.

Brecher, S. J., Bender, M. M., Wilkening, V. L., McCABE, N. M., \& Anderson, E. M. (2000). Status of nutrition labeling, health claims, and nutrient content claims for processed foods: 1997 Food Label and Package Survey, Journal of the American Dietetic Association, 100(9), 1057-1062.

Cairns, G., Angus, K. \& Hastings, G. (2009). The extent, nature and effects of food promotion to children: A $\mathrm{revie}$ of $\mathrm{the}$ e vidence to $\mathrm{D}$ e c 2008 , Ge neva: W H O http://www.who.int/dietphysicalactivity/Evidence_Update_2009.pdf

Cannoosamy, K., Pugo-Gunsam, P., \& Jeewon, R. (2014). Consumer knowledge and attitudes toward nutritional labels, Journal of Nutrition Education and Behavior, 46(5), 334-340.

Consumers International (2008). The junk food trap- marketing unhealthy food to children in Asia Pacific, United Kingdom, London. http://www.consumersinternational.org/news-and-media/publications/junk-food-trap-asurvey-of-food-marketing-to-children-in-asia-and-the-pacific-region.

Co-operative Wholesale Society Ltd., U.K. (2002). Lie of the label II: Why dishonest labelling is past its sell-by date.

Cowburn, G., \& Stockley, L. (2005). Consumer understanding and use of nutrition labelling: a systematic review, Public Health Nutrition, 8(1), 21-28.

Dharni, K., \& Gupta, K. (2015). Exploring antecedents of healthy food choices: An Indian experience, International Journal of Consumer Studies, 39(2), 101-108. 
Drichoutis, A. C., Lazaridis, P., \& Nayga Jr, R. M. (2006). Consumers' use of nutritional labels: A review of research studies and issues, Academy of Marketing Science Review, 9, 1-22.

Dutta, S., \& Patel, D. (2017). Study of consumer awareness on food labelling and use of pack information for purchase of pre-packaged food products, The International Journal of Indian Psychology. 4(4), 63-72.

Food Safety and Standards Authority of India (Ministry of Health and Family Welfare) (2012). Draft Regulation o $\mathrm{n} \quad \mathrm{L}$ a b e $11 \mathrm{i} \mathrm{ng}$ ( c 1 a i m s ). http://www.fssai.gov.in/Portals/0/Pdf/covering\%20letter\%20for\%20draft\%20regulation.pdf

Food Safety and Standards ${ }^{u s}$ Authority of Indias (2012). Indian Food Code. http://www.fssai.gov.in/portals/0/pdf/indian_food_code(25-06-2012).pdf

Genannt Bonsmann, S. S., Celemín, L. F., Larrañaga, A., Egger, S., Wills, J. M., Hodgkins, C., \& Raats, M. M. (2010). Penetration of nutrition information on food labels across the EU-27 plus Turkey, European Journal of Clinical Nutrition, 64(12), 1379.

Govindasamy, R., \& Italia, J. (1999). Evaluating consumer usage of nutritional labeling: The influence of socioeconomic characteristics (No. 36734), Rutgers University, Department of Agricultural, Food and Resource Economics. http://ageconsearch.umn.edu/record/36734/files/pa990199.pdf

Hawley, K. L., Roberto, C. A., Bragg, M. A., Liu, P. J., Schwartz, M. B., \& Brownell, K. D. (2013). The science on front-of-package food labels, Public Health Nutrition, 16(3), 430-439.

Hawkes, C., \& World Health Organization (2004). Nutrition labels and health claims: The global regulatory

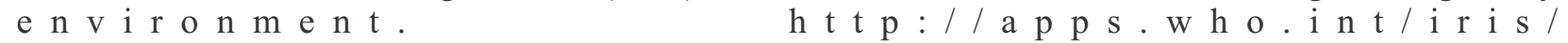
bitstream/handle/10665/42964/9241591714.pdf?sequence=1\&isAllowed=y

Intodia, V. (2011). Mandatory Nutrition Labeling and Implications for Food Companies in India, Asian Journal of Food and Agro-Industry, 4(4), 255-260.

Kasapila, W., \& Shaarani, S. M. (2013). A survey of nutrition labelling on packaged foodstuffs sold in Malawi: Manufacturer practices and legislative issues, Food Control, 30(2), 433-438.

Kelly, B., Hughes, C., Chapman, K., Louie. J.C-Y., Dixon, H. \& King, L. (2008). Front-of-pack Food Labelling Report: Traffic Light Labelling Gets the Green Light, Sydney (AUST): Cancer Council New South Wales. http://www.cancercouncil.com.au/nutrition/foodlabellingreport

Kresic, G., Liovic, N., \& Pleadin, J. (2018). Effects of menu labelling on students' food choice: A preliminary study, British Food Journal. https://doi.org/10.1108/BFJ-03-2018-0188

Kumar, N., \& Kapoor, S. (2017). Do labels influence purchase decisions of food products? Study of young consumers of an emerging market, British Food Journal, 119(2), 218-229.

Legault, L., Brandt, M. B., McCabe, N., Adler, C., Brown, A. M., \& Brecher, S. (2004). 2000-2001 food label and package survey: an update on prevalence of nutrition labeling and claims on processed, packaged foods, Journal of the American Dietetic Association, 104(6), 952-958.

Levy, A.S., Fein, S.B., \& Schucker, R.E. (1996). Performance characteristics of seven nutrition label formats, Journal of Public Policy \& Marketing, 15(1), 1-15.

Lobstein, T. \& Davies, S. (2008). Defining and labelling 'healthy' and 'unhealthy' food, Public Health Nutrition, 12(3), 331-340.

Lv, J., Chen, Y., Wang, S., Liu, Q., Ren, Y., Karrar, S., \& Li, L. (2011). A survey of nutrition labels and fats, sugars, and sodium ingredients in commercial packaged foods in Hangzhou, China, Public Health Reports, 126(1), 116.

Morgan Stanley Research (2016). Are groceries the next big driver of global ecommerce? https://www.morganstanley.com/ideas/online-groceries-could-be-next-big-ecommerce-driver

National Institute of Nutrition (2011). Dietary Guidelines for Indians-A Manual, National Institute of Nutrition, Hyderabad, India. http://ninindia.org/dietaryguidelinesforninwebsite.pdf

Rajput, N. (2015). Packaged Food Market by Product Type (Ice Creams, Pasta, Cheese, Yogurt, Nuts, Biscuits, Baby Food, Soups, Potato Chips, Instant Noodles, Non-Alcoholic Drinks, Breakfast Cereals) - Opportunity Analysis and Industry Forecast, 2014-2020. https://www.alliedmarketresearch.com/packaged-food-market 
Sacks, G., Veerman, J. L., Moodie, M. \& Swinburn, B. (2011). 'Traffic-light' nutrition labelling and 'junk-food' tax: A modelled comparison of cost-effectiveness for obesity prevention, International Journal of Obesity, 35(7), 1001-1009.

Saha, S., Vemula, S. R., Mendu, V. V. R., \& Gavaravarapu, S. M. (2013). Knowledge and practices of using food label information among adolescents attending schools in Kolkata, India, Journal of Nutrition Education and Behavior, 45(6), 773-779.

Sarkar (2017). Check out expiry of food ordered online, The times of India. http://timesofindia.indiatimes.com/business/india-business/check-out-expiry-of-food-orderedonline/articleshow/57697693.cms

Satia, J. A., Galanko, J. A., \& Neuhouser, M. L. (2005). Food nutrition label use is associated with demographic, behavioral, and psychosocial factors and dietary intake among African Americans in North Carolina, Journal of the American Dietetic Association, 105(3), 392-402.

Shine, A., O'Reilly, S., \& O'Sullivan, K. (1997). Consumer use of nutrition labels, British Food Journal, 99(8), 290-296.

Singh, M., Iyer, U. \& Chandorkar, S. (2013). Nutrition Labeling Compliance of Branded Processed Packaged Foods with Indian Food Laws (FSSAI, 2011 Regulations), International Journal of Food and Nutritional Sciences, 2(4), 14-19.

Singla, M. (2010). Usage and understanding of food and nutritional labels among Indian consumers, British Food Journal, 112(1), 83-92.

Soni. P. (2016). Nutritional quality of foods marketed to children in north India, Journal of Marketing Vistas, 6(2), 40-49.

Srivastava, N., \& Ghufran, A. (2013). Analysis of nutritional information disclosure on labels of milk based malted health drinks in India, Integral Review: A Journal of Management, 6(1), 61-69.

Popkin, B. M., Horton, S., Kim, S., Mahal, A., \& Shuigao, J. (2001). Trends in diet, nutritional status, and dietrelated non-communicable diseases in China and India: The economic costs of the nutrition transition, Nutrition Reviews, 59(12), 379-390.

Vemula, S. R., Gavaravarapu, S. M., Mendu, V. V. R., Mathur, P., \& Avula, L. (2014). Use of food label information by urban consumers in India- A study among supermarket shoppers, Public Health Nutrition, 17(9), 2104-2114.

Vijaykumar, S., Lwin, M. O., Chao, J., \& Au, C. (2013). Determinants of food label use among supermarket shoppers: A Singaporean perspective, Journal of Nutrition Education and Behavior, 45(3), 204-212.

World Health Organization (2011). Global status report on non-communicable diseases, Geneva. http://www.who.int/nmh/publications/ncd_report_full_en.pdf 
